\title{
Ocular motility in alternating squints: an electro-oculographic study
}

\author{
PREM PRAKASH, A. K. GROVER, P. K. KHOSLA, AND D. K. GAHLOT \\ From the Dr Rajendra Prasad Centre for Ophthalmic Sciences, All-India Institute of Medical Sciences, \\ New Delhi 29, India
}

SUMmaRY Ocular movements were studied electro-oculographically in 10 normal subjects and 10 patients with alternating strabismus. Fixation and pursuit movements and to a less extent the saccadic movements were observed to be abnormal in patients with alternating strabismus. The defect in pursuit movements was shown to be statistically significant. There was no correlation between the extent of ocular motor abnormalities and the angle of deviation or the size of facultative suppression scotoma. The possible common pathological mechanism leading to the ocular motor abnormalities qualitatively similar to those reported earlier in strabismus and anisometropic amblyopes are discussed.

\begin{abstract}
Abnormal ocular motility resulting from abnormal sensory adaptations has been demonstrated in amblyopic eyes as well as the fellow eyes of amblyopic subjects. Mackenson' ${ }^{1}$ reported the existence of unsteady fixation in amblyopes for the first time. Later, saccades ${ }^{2}$ and pursuit movements ${ }^{3-7}$ were demonstrated in amblyopic subjects, both in the amblyopic eyes as well as the fellow eyes of amblyopic subjects. Mackensen' ${ }^{1}$ reported the existence of studied. However, no study of ocular motility in other forms of sensory adaptations, such as alternating squint (alternate suppression), has been undertaken. Our intention was to find out if an abnormal sensory experience, in the absence of an obligatory suppression, also leads to abnormalities of ocular motility. This work was therefore undertaken to study ocular motility in subjects with alternating squint.
\end{abstract}

\section{Material and methods}

The study was carried out on 10 normal subjects and 10 subjects with alternating strabismus from the ocular motility and amblyopia clinic of the $\mathrm{Dr}$ Rajendra Prasad Centre for Ophthalmic Sciences, New Delhi. A full orthoptic examination was carried out in all subjects. Suppression scotoma was charted by means of foveal fusion slides on the synoptophore.

Ocular motility was recorded electro-oculographi-

Correspondence to Dr Prem Prakash. Dr Rajendra Prasad Centre for Ophthalmic Sciences, Ansari Nagar. New Delhi 110016. India. cally on a multichannel recorder, Mingograph-800. The recordings were carried out at a constant paper speed of $5 \mathrm{~mm} / \mathrm{s}$, each small square on the graph paper being $1 \mathrm{~mm}$. Fixation, saccades, and pursuit movements were recorded both in dark- and lightadapted states under standardised conditions for each eye.

Fixation was recorded while the patient looked at a target straight ahead of him. Saccadic movements were recorded as the patient looked from a fixation light on one side to the other, an excursion of $30^{\circ}$. Pursuit movements were recorded with an excursion of $30^{\circ}$ to either side.

Analysis of results was carried out by certain modifications of the method described by von Noorden and Mackensen. ${ }^{4}$ Grading of fixation, saccades, and pursuit movements was as shown in Figs. 1, 2, and 3. Two other parameters, critical frequency (CF) and frequency of disintegration (FD), were utilised to evaluate the pursuit movements, which allowed the ocular motor abnormalities to be tested statistically.

\section{Results}

Critical Frequency $(C F)$. The frequency at which the sine curve first shows a tendency to disintegration was taken as the critical frequency. At this frequency larger jerks were superimposed on the pursuit and the eye slipped from the target for relatively large durations. 


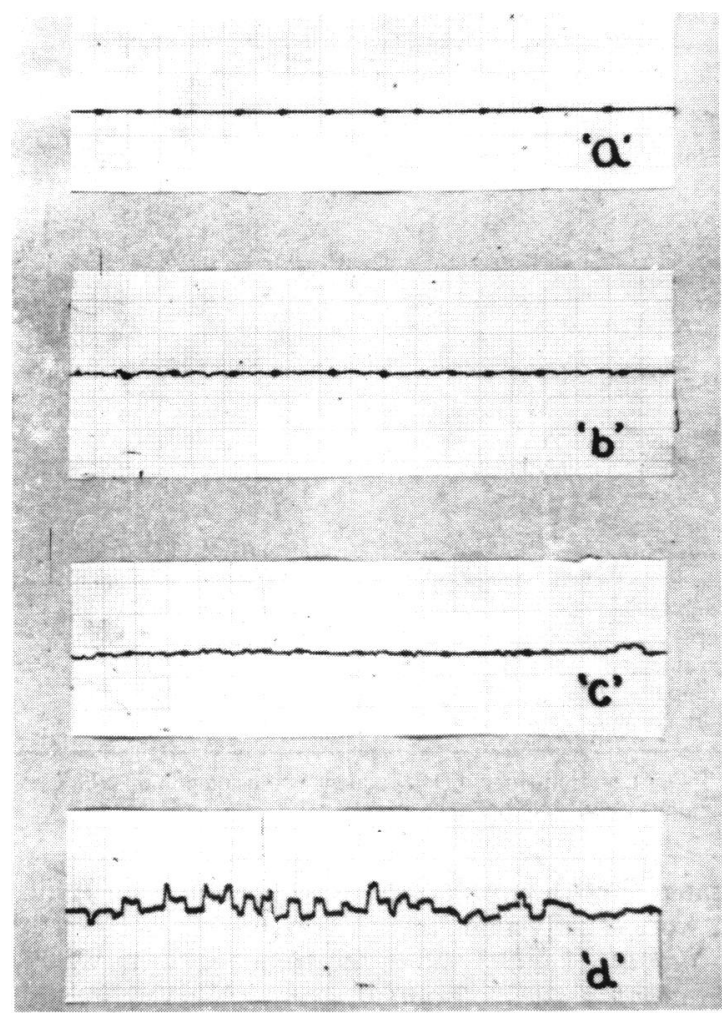

Fig. 1 Different grades of fixation. (a) Steady fixation. (b) Superimposed small jerks. (c) Pronounced unsteadiness of fixation. (d) Coarse irregular large movements during fixation.

Table 1 Fixation

\begin{tabular}{llllll}
\hline Grade & \multicolumn{2}{l}{ Normals } & & \multicolumn{2}{l}{ Alternators } \\
\cline { 2 - 3 } & Dark & Light & & Dark & Light \\
\hline A & 8 & 8 & 5 & 4 \\
B & 2 & 1 & 4 & 4 \\
C & 0 & 1 & 1 & 0 \\
D & 0 & 0 & 0 & 2 \\
\hline
\end{tabular}

Table 2 Saccades

\begin{tabular}{llllll}
\hline \multirow{2}{*}{ Grade } & \multicolumn{2}{l}{ Normals } & & \multicolumn{2}{l}{ Alternators } \\
\cline { 2 - 3 } & Dark & Light & & Dark & Light \\
\hline A & 10 & 9 & 9 & 7 \\
B & 0 & 1 & 1 & 2 \\
C & 0 & 0 & 0 & 1 \\
D & 0 & 0 & 0 & 0 \\
\hline
\end{tabular}

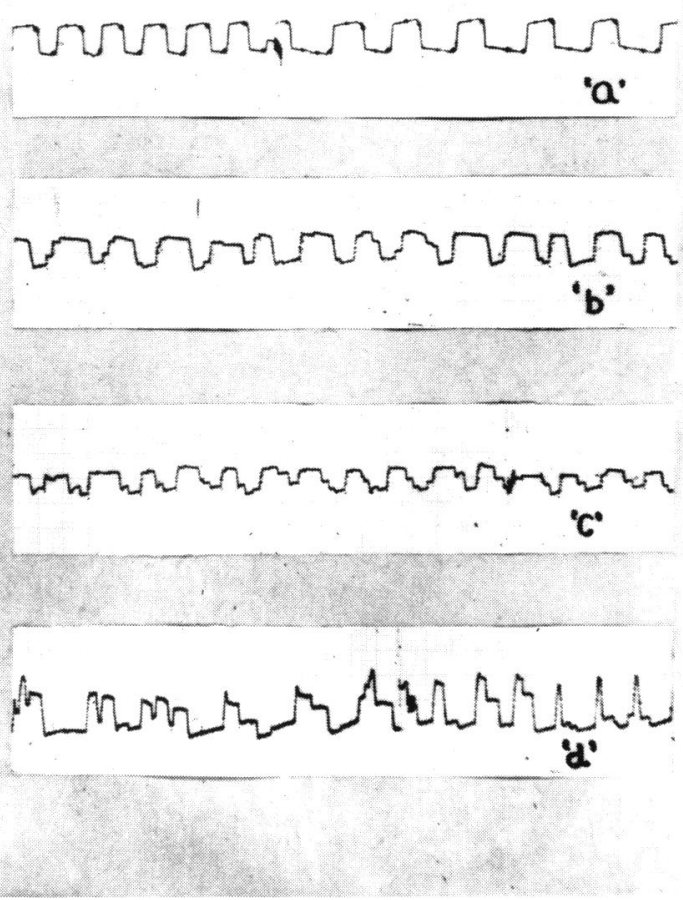

Fig. 2 Different grades of saccadic movements. (a) Regular smooth saccadic movements. (b) Occasional superimposed jerks in the saccades. (c) Saccades broken into several smaller saccades - mild under- or over-shoots. (d) Saccades almost entirely replaced by jerky deviations, cross-over or undershoots.

Frequency of disintegration $(F D)$. The frequency at which pursuit was totally replaced by saccades and no evidence of pursuit could be seen was termed the frequency of disintegration.

Observations. Abnormalities of ocular motility were often observed in the patients with alternating strabismus. The abnormalities were qualitatively similar to those observed in amblyopic subjects. ${ }^{7}$

Fixation. This was often observed to be unsteady (Figs. 4, 6, 7). Table 1 shows the frequency of abnormalities in fixation in comparison with those in normal subjects. It is apparent that $60 \%$ of the alternators had unsteady fixation in the light-adapted state and $50 \%$ in the dark-adapted state. Severer grades of abnormality were infrequent.

Saccades. Abnormalities in saccades were infrequent, having been observed in only $30 \%$ of subjects in the light- and $10 \%$ in the dark-adapted 


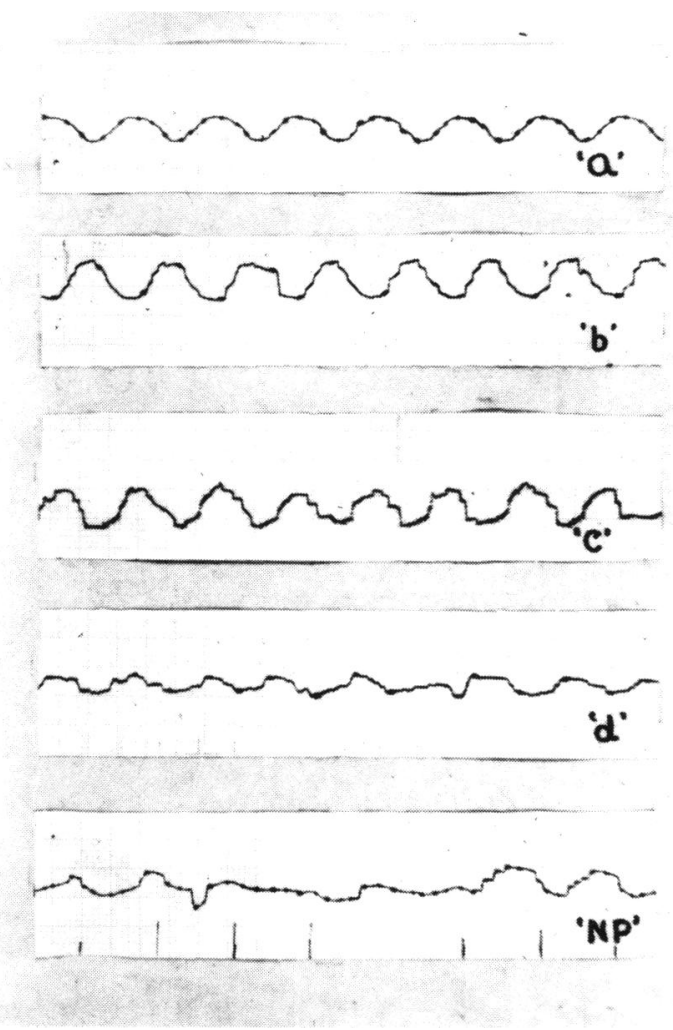

Fig. 3 Different grades of pursuit movements. (a) Smooth pursuit movements. (b) Superimposed saccadic intrusions on the same shaped curve. (c) Pronounced disturbance of pursuit in form of step ladder pattern. (d) Gross deformation of pursuit movements curve with large intrusions superimposed. (e) $N P=$ No pursuit is evident.
Table 3 Pursuit movements

\begin{tabular}{|c|c|c|c|c|}
\hline \multirow[t]{2}{*}{ Grade } & \multicolumn{2}{|c|}{$\begin{array}{l}\text { Normals } \\
\text { (no. of eves) }\end{array}$} & \multicolumn{2}{|c|}{$\begin{array}{l}\text { Alternators } \\
\text { (no. of eves) }\end{array}$} \\
\hline & Dark & Light & Dark & Light \\
\hline A & 12 & 12 & 5 & 4 \\
\hline B & 5 & 4 & 6 & 7 \\
\hline C & 2 & 3 & 5 & 3 \\
\hline D & 1 & 1 & 3 & 4 \\
\hline$E(N P)$ & 0 & 0 & 1 & 2 \\
\hline Asymmetry & 0 & 0 & 3 & 3 \\
\hline $\begin{array}{l}\text { Mean CF } \\
\text { (cps) } \\
\text { p value as } \\
\text { compared } \\
\text { with normal }\end{array}$ & $0 \cdot 62 \pm 0 \cdot 19$ & $0 \cdot 60 \pm 0 \cdot 19$ & $0 \cdot 49 \pm 0 \cdot 17$ & $\begin{array}{l}0 \cdot 44 \pm 0 \cdot 19 \\
0 \cdot 02\end{array}$ \\
\hline $\begin{array}{l}\text { Mean FD } \\
\text { (cps) } \\
\text { p value as } \\
\text { compared } \\
\text { with normal }\end{array}$ & $0 \cdot 92 \pm 0 \cdot 19$ & $0 \cdot 84 \pm 0 \cdot 18$ & $0 \cdot 70 \pm 0 \cdot 20$ & $0 \cdot 63 \pm 0 \cdot 21$ \\
\hline
\end{tabular}

$\mathrm{CF}=$ Critical frequency. $\mathrm{FD}=$ Frequency of disintegration. $\mathrm{NS}=$ Not significant. $\mathrm{NP}=$ No pursuit.

state. These abnormalities, as is apparent from Table 2, were usually mild.

Pursuit. Table 3 shows the frequency with which different grades of pursuit were observed in the subjects with alternating strabismus and normal subjects. It is apparent that a much larger number of eyes showed abnormal grades of pursuit than the controls (Figs. 4, 5, 6, 7). No marked difference was apparent between the frequency of abnormalities in the dark- and light-adapted states. The mean critical
Fig. 4 Ocular motility in a subject with alternating squint (lightadapted, left eye). Fixation $(F)$. Saccadic intrusions as well as superimposed large saccades. Saccadic (S): Saccadic movements are normal, though fixation at either end is unsteady. Pursuit (P):

Pursuit has been totally replaced by saccadic movements; no sineshaped curve present. (Numerals in pursuit movements indicate speed in cps; paper speed $5 \mathrm{~mm} / \mathrm{s}$, each small square $1 \mathrm{~mm}$ ).

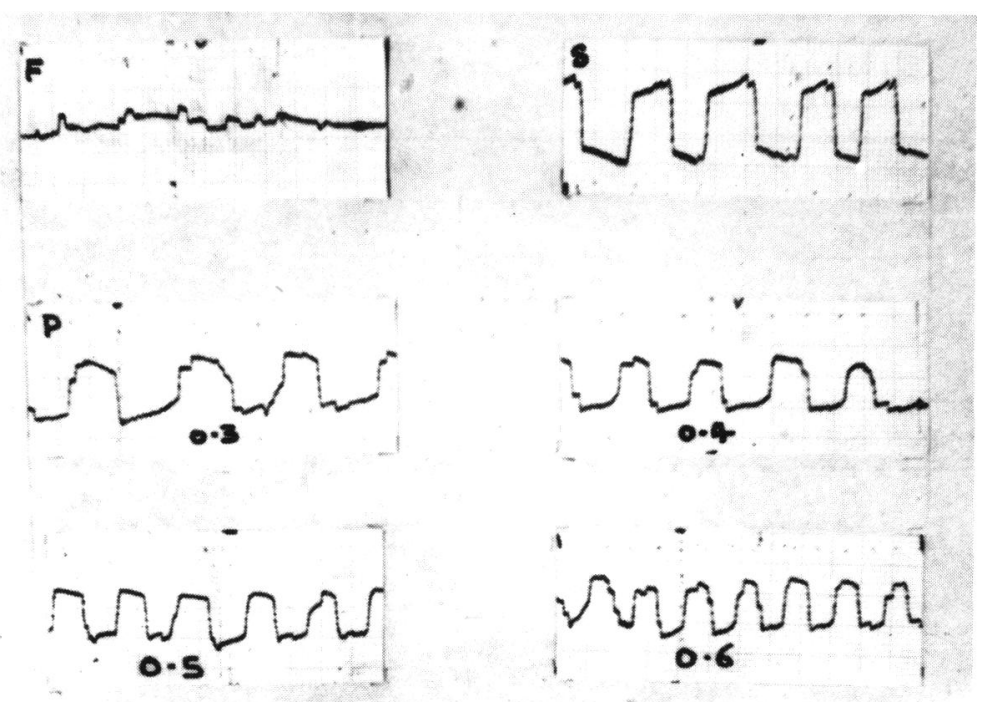




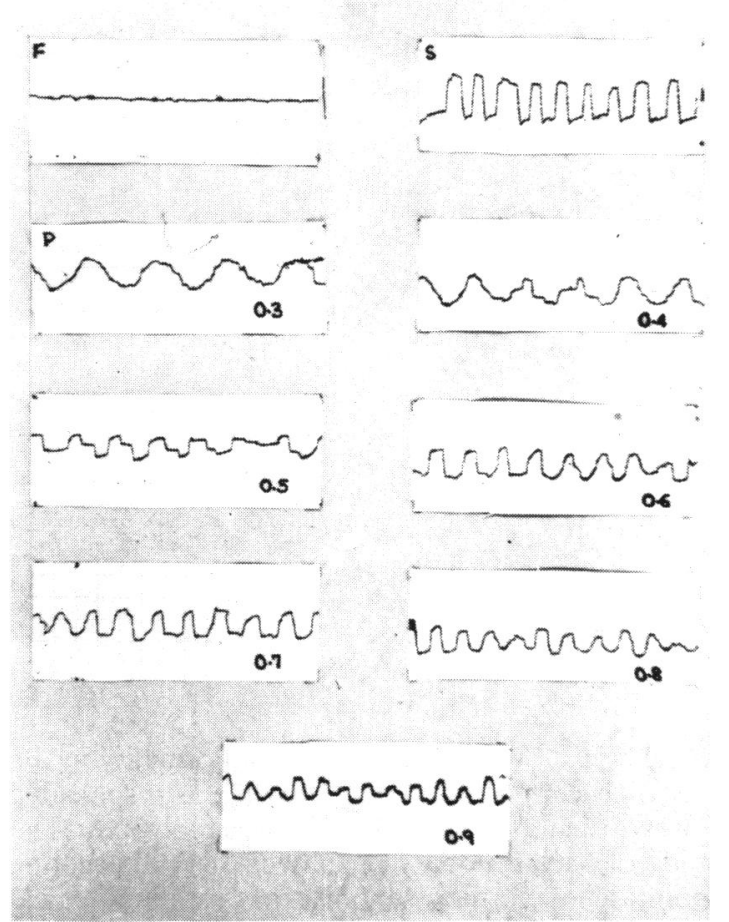

Fig. 5 Ocular motility in a subject (dark-adapted, left eve) Fixation (F): Saccadic intrusions as well as occasional periods of drifts are present. Saccades $(S)$ : Normal. Pursuit $(P)$ : Step ladder pursuit at $0 \cdot 3 \mathrm{cps}$. Superimposed large saccades on pursuit at $0.4 \mathrm{cps}$. Asvmmetry of pursuit is evident at $0 \cdot 5,0 \cdot 6,0 \cdot 7,0 \cdot 8 \mathrm{cps}$ ). (Numerals in pursuit movements indicate speed in cps. Paper speed $5 \mathrm{~mm} / \mathrm{s}$, each small square $1 \mathrm{~mm}$ ).

frequency $(\mathrm{CF})$ in the alternators in the dark-adapted state was $0 \cdot 49 \pm 0 \cdot 17$ counts per second (cps) as compared with $0 \cdot 62 \pm 0 \cdot 19 \mathrm{cps}$ in normal subjects and $0 \cdot 44 \pm 0 \cdot 19 \mathrm{cps}$ in comparison with $0 \cdot 60 \pm 0 \cdot 19 \mathrm{cps}$ in control subjects in the light-adapted state. The values were significantly lower in the alternators $(0.05>p>0.02$ in dark- and light-adapted states respectively).

The mean frequency of disintegration (FD) in the alternators in the dark-adapted state was $0 \cdot 70 \pm 0 \cdot 20$ cps (normal subjects $0.92 \pm 0 \cdot 19 \mathrm{cps}$ ) and $0 \cdot 63 \pm 0 \cdot 21$ cps (normal subjects $0 \cdot 84 \pm 0 \cdot 18 \mathrm{cps}$ ). The values were significantly lower in alternators $(p<0.01)$ in both dark- and light-adapted states. The values of $\mathrm{CF}$ and FD in dark- and light-adapted states were not significantly different from each other.

Asymmetry of pursuit in nasal and temporal movement (Figs. 5,6) was observed in 3 eyes of 2

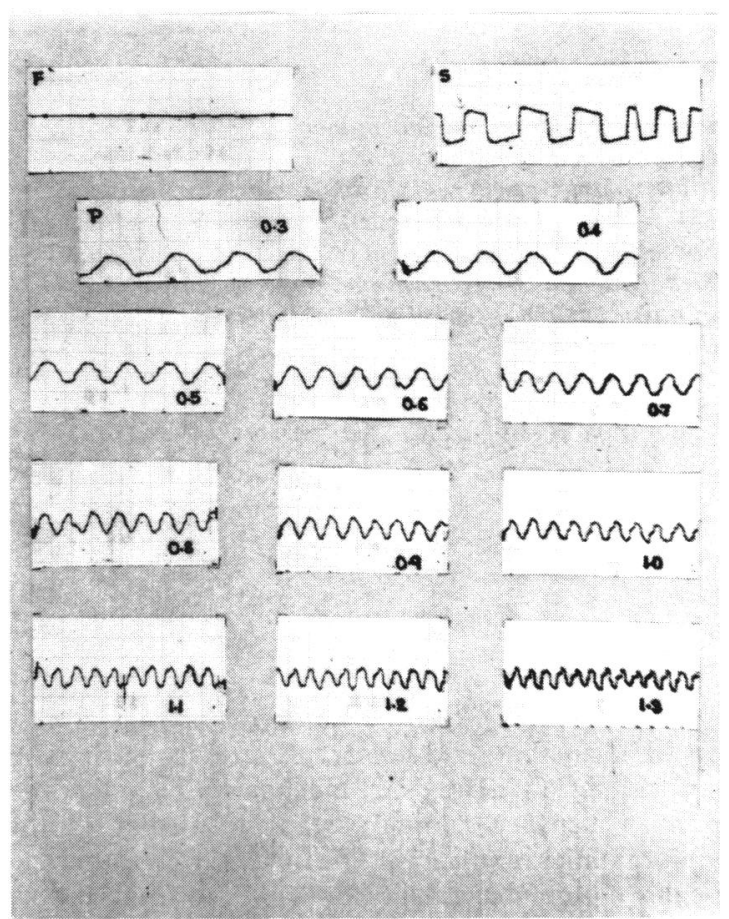

Fig. 6 Ocular motility in another subject with alternating squint (dark-adapted, left eve). Fixation $(F)$ : Normal, steady fixation. Saccades $(S)$ : Normal. Pursuit $(P)$ : Smooth pursuit at lower speeds, except for occasional saccadic intrusions. Obvious asymmetry of pursuit at higher speeds $(0 \cdot 9,1 \cdot 0,1 \cdot 1$ cps). (Numerals in pursuit movements indicate speed in cps. Paper speed $5 \mathrm{~mm} / \mathrm{s}$, each small square $1 \mathrm{~mm}$ ).

subjects. This asymmetry could not be related to the existence of asymmetry of facultative suppression scotoma in these subjects.

Correlation of different parameters with ocular motor abnormalities. No correlation was found between the extent of ocular motor abnormalities and either angle of deviation or size of facultative suppression scotoma.

\section{Discussion}

This study shows that ocular motor abnormalities like those observed in amblyopic subjects exist in patients with alternating squint as well. Thus even in alternators, in whom obligatory suppression is absent, some common factor may operate in the causation of ocular motor abnormalities like those in strabismic and anisometropic amblyopes. This factor 
Fig. 7 Ocular motility in another subject with alternating squint (dark-adapted, right eye). Fixation (F): Periods of drift are present. Saccades (S): Normal. Pursuit (P): Step ladder pattern (cog wheeling) of pursuit at low speeds. Early disintegration of pursuit.

(Numerals in pursuit movements indicate speed in cps. Paper speed 5 $\mathrm{mm} / \mathrm{s}$, each small square $1 \mathrm{~mm}$ ).

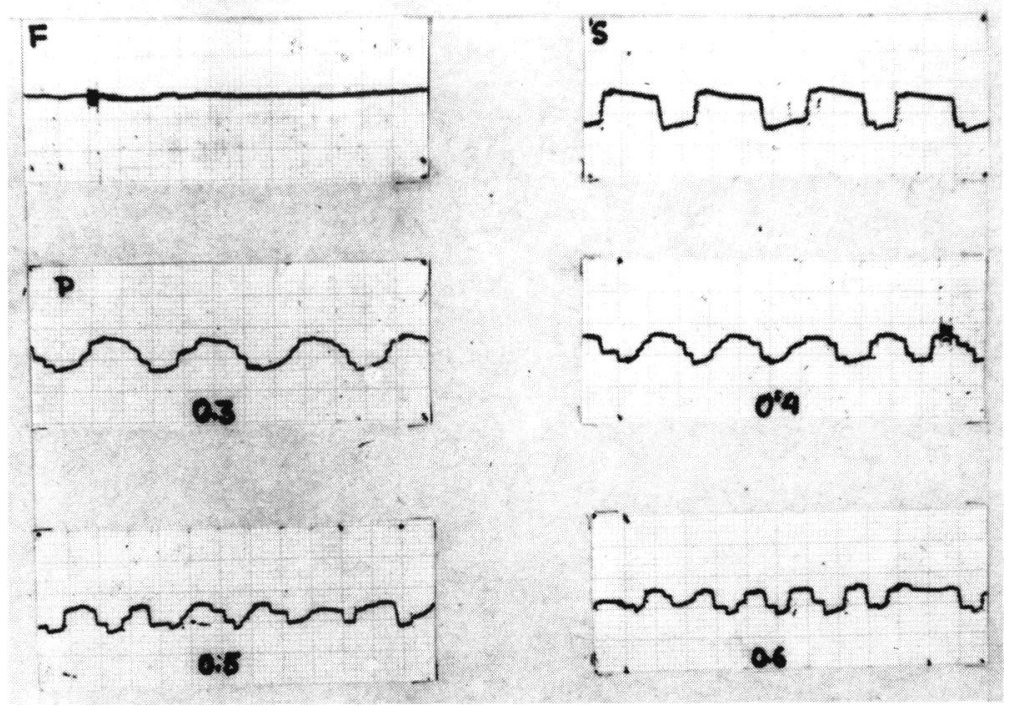

could be an abnormal sensory experience during the 'critical period.' The exact mechanism by which the primary sensory anomaly leads to ocular motor abnormalities is not clear. The results suggest that the ocular motor abnormalities may result from abnormalities in the binocularly driven cells of the occipital cortex, which in turn may result from an abnormal sensory input during the critical period. These binocularly driven cells are the source of afferent stimuli to the occipital and probably the frontal oculomotor system. That an abnormal input to the occipital oculomotor system could affect the 'position maintenance system' and the 'pursuit system' is quite possible. The observations made in the present study showed the defect in fixation and pursuit movements to be much more frequent while the defect in saccadic movements was markedly less frequent, suggesting that the occipital oculomotor system is affected to a greater extent than the frontal oculomotor system.

A number of workers have demonstrated an alteration in the dominance of eyes and a decrease in the number of binocularly driven cells of the striate cortex by abnormal sensory stimulation in the critical period. Such observations have been made on young kittens by monocular occlusion ${ }^{89}$ and by producing artificial strabismus ${ }^{10}$ or by alternate occlusion. ${ }^{10}$ Similar results have been demonstrated in monkeys by stimulus deprivation ${ }^{11}$ and by induced strabismus. ${ }^{12}$ Thus it is conceivable that an abnormal sensory experience in the critical period, such as strabismus, anisometropia, or alternating strabismus may affect the binocular cells of the occipital cortex.

This study is therefore in agreement with that of
Fukai et al. ${ }^{13}$ who postulated an abnormality in the binocular cells of the occipital cortex as responsible for abnormal ocular motility in the amblyopes. The study of ocular motility in subjects with alternating squint lends further support to this pathological mechanism.

\section{References}

1 Mackensen G. Einfluss pleoptischer Behandlung auf die Blickbewegungen schwachsichtiger Augen. Klin Monatsbl Augenheilkd 1957; 131: 640-50.

2 von Noorden GK, Burian HM. An electro-ophthalmographic study of the behaviour of the fixation of amblyopic eyes in lightand dark-adapted state: a preliminary report. Am J Ophthalmol 1958; 46: 68-77.

3 von Noorden GK, Mackensen G. Pursuit movements of normal and amblyopic eyes-an electro-ophthalmographic study. II. Pursuit movements of amblyopic patients. Am J Ophthalmol 1962; 53: 477-87.

4 von Noorden GK, Mackensen G. Phenomenology of eccentric fixation. Am J Ophthalmol 1962; 53: 642-61.

5 Fukai S, Tsusui J. Asymmetric version in pursuit eye movements under extrafoveal fixation. Jpn Ophthalmol 1973; 17: 30-9.

6 Ciuffreda KJ, Kenyon RV, Stark L. Abnormal saccadic substitution during small-amplitude pursuit tracking in amblyopic eyes. Invest Ophthalmol Visual Sci 1979; 18: 506-16.

7 Prakash P, Grover AK, Khosla PK, Gahlot DK. Ocular motility in amblyopic and fellow eye. Parts I and II Proceedings All India Ophthalmic Society in press.

8 Wiesel TN, Hubel DH. Comparison of the effects of unilateral and bilateral eye closure on cortical unit responses in kittens. $J$ Neurophysiol 1965; 28: 1029-40.

9 Blakemore C, van Sluyters RC. Reversal of the physiological effects of uniocular deprivation in kittens. Further evidence for a sensitive period. $J$ Physiol 1974; 237: 195-216.

10 Hubel DH, Wiesel TN. Binocular interaction in striate cortex of kittens reared with artificial squint. J Neurophysiol 1965; 28: 1041-59. 
11 von Noorden GK. Dowling JE, Ferguson DC. Experimental amblyopia in monkeys. (I) Behavioural studies of stimulus deprivation amblyopia. Arch Ophthalmol 1970; 84: 206-14.

12 von Noorden GK, Dowling JE. Experimental amblyopia in monkeys. (II) Behavioural studies in strabismic amblyopia. Arch Ophthalmol 1970; 84: 215-20.

13 Fukai S, Tsutsui J, Nakamura Y. Abnormal pursuit movements of the fellow eye in amblyopia with strabismus. In: Moore S, et al, ed. Orthoptics Past, Present, Future. New York: Stratten Intercontinental 1975: 75-91. 